\title{
On the Question of Methodology of Hybrid Sliding Bearings Estimated Load Capacity and Durability Evaluation
}

\author{
Myron Chernets ${ }^{1 *}$, Mykhaylo Pashechko ${ }^{2}$, Anatolii Kornienko', \\ Juriy Chernets' ${ }^{1}$, Svetlana Fedorchuk' \\ 1 Department of Engineering, Standardization and Certification, National Aviation University, Liubomyra \\ Huzara ave. 1, 03058 Kiev, Ukraine \\ 2 Department of Fundamentals of Technology, Lublin University of Technology, ul. Nadbystrzycka 36, 20-618 \\ Lublin, Poland \\ *Corresponding author's e-mail: myron.czerniec@gmail.com
}

\begin{abstract}
The computational method of hybrid (metal-polymer) sliding bearings according to the load capacity and durability of the bushing made of polyamide filled with glass or carbon dispersed fibers was presented. The initial contact pressures were calculated and the influence of bushing wear on their relative reduction was investigated. The wear resistance of bearings with bushings made of both polymer composites was also evaluated. Regularities of their change from loading, diameter of the bushing and radial clearance were established.
\end{abstract}

Keywords: metal-polymer sliding bearings, polyamide reinforced composite, computational method, maximum contact pressures, durability

\section{INTRODUCTION}

In various branches of the technosphere (mechanical engineering, aircraft construction, instrument making, automobile construction, food processing, pharmaceutical, textile, pulp and paper, chemical industry, etc.), as well as in other various areas of human activity, sliding bearings with a composite bushing (micro, miniature, small, medium and large diameters) are used increasingly often. This is due to the fact that there are many applications where they have advantages over rolling bearings. They can work well in dry friction without the need for lubrication and under the conditions that make it impossible to use and replace lubricants due to the technological requirements or special operating conditions. They also have increased damping capacity and other positive qualities.

The polymer composite materials used for the manufacturing of sliding bearing bushings have the strength characteristics and modulus of elasticity 1-2 orders of magnitude lower than typical metallic materials, which fundamentally changes the conditions of contact and tribocontact interaction. The most common are polyamides, polycarbonates, polyimides, polyacetals, polyamidoimides, polytetrafluoroethylene, polyesterketones and others with different fillers that increase their wear resistance. More and more new types of such materials are appearing. However, their choice in engineering practice is practically not based on the scientifically sound methods of design calculation.

The simplified or approximate calculation [3-7, 14-16] methods, including and numerical research methods for metal [11-13] and metalpolymer [8-10] sliding bearings known in the literature have not yet found practical application. This is obviously because they use the wellknown Archard law of abrasive wear, which assumes a linear dependence of wear on the contact pressure and the path of sliding friction. However, this type of wear by the micro-cutting 
mechanism is practically not allowed even in dry friction bearings. Therefore, estimates are very approximate and with sufficient complexity of their implementation, they are unpromising in the engineering practice.

Therefore, the creation of sound, efficient and fairly simple methods for estimating the load capacity, wear and durability of metal-polymer bearings at the design stage remains an urgent task. This publication is devoted to solving this current problem. For this purpose, the methodology of studying the wear kinetics during sliding friction was used as a process of frictional-fatigue destruction of the near-surface layers of tribosystem elements under the influence of specific friction forces [1]. The methods for calculating the wear of metal contact elements of sliding bearings, including bearings with a small roundness of the shaft and bushing contours, developed on its basis were also employed $[1,2]$.

\section{METHODS}

The calculation of such a sliding tribosystem is performed as a plane contact problem of the theory of elasticity about the internal contact of cylindrical bodies of close radii. The design scheme of the bearing is shown in Figure 1.

The bearing journal is subjected to a radial load $N$, which in the plane problem is assigned to the length $l$ of the journal. That is, a reduced

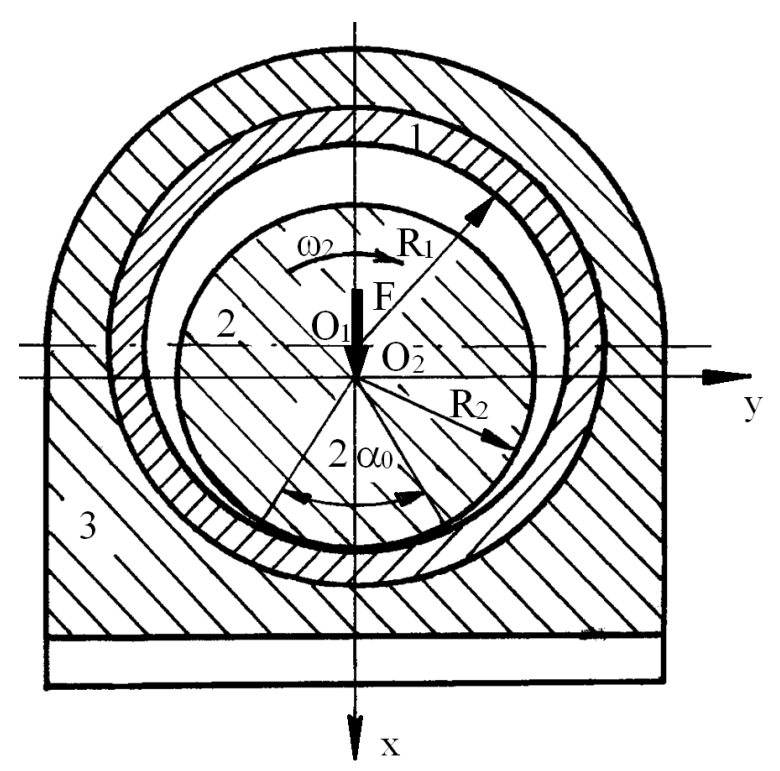

Fig. 1. Scheme of the sliding bearing concentrated load $F=N / l$ is applied to the center $\mathrm{O}_{2}$ of the nominally circular disk. There is a radial clearance $\varepsilon=R_{1}-R_{2} \geq 0<<R$ between it and the ring 1 (bearing bushing). The shaft is made of steel and the bushing is made of the polyamide composite reinforced with dispersion glass or carbon fibers. Therefore, their wear resistance and elastic properties will be significantly different. Disc 2 rotates at a constant angular velocity $\omega_{2}$. Under the loading of disk 2 by the force $F$, an initial contact pressure $p_{\alpha}$ is arising in the contact area $2 R_{2} \alpha_{0}$. The distribution of the pressure $p_{\alpha}$ and the contact angle $2 \alpha_{0}$ are unknown and should be determined as a result of the problem solution. Under wear, both the pressure value and the angle of contact will change, which is also subject to study.

The calculation of the initial static contact pressures $p_{\alpha}$ is performed by means of the singular integro-differential equation [1]:

$$
\begin{gathered}
c_{1} \int_{-\alpha_{0}}^{\alpha_{0}} \operatorname{ctg} \frac{\alpha-\theta}{2} p_{\theta}^{\prime} d \theta=c_{2} p_{\alpha}+c_{3} \int_{-\alpha_{0}}^{\alpha_{0}} p_{\alpha} d \alpha+ \\
+c_{4} \cos \alpha \int_{-\alpha_{0}}^{\alpha_{0}} p_{\alpha} \cos \alpha d \alpha+\frac{\varepsilon}{R^{2}}
\end{gathered}
$$

where: $p_{\theta}^{\prime}=\mathrm{d} p / \mathrm{d} \theta$;

$\alpha$ is the polar angle;

$0 \leq \alpha \leq \theta$;

$$
\begin{aligned}
& c_{1}=\frac{1}{8 \pi}\left(\frac{1+\kappa_{1}}{G_{1} R_{1}}+\frac{1+\kappa_{2}}{G_{2} R_{2}}\right) ; \\
& c_{2}=\frac{1}{4}\left(\frac{1-\kappa_{1}}{G_{1} R_{1}}-\frac{1-\kappa_{2}}{G_{2} R_{2}}\right) ; \\
& c_{3}=\frac{1+\kappa_{1}}{8 \pi G_{1} R_{1}} \\
& c_{4}=\frac{1}{2 \pi}\left(\frac{\kappa_{1}}{G_{1} R_{1}}+\frac{1}{G_{2} R_{2}}\right) ; \quad R_{1} \approx R_{2}=R ; G_{1}, G_{2} \\
& \text { are the shear modulus of materials; } \\
& v_{1}, v_{2} \text { are the Poisson coefficients; } \\
& \kappa=3-4 v \text { is the Muskhelishvili constant. }
\end{aligned}
$$

The approximate solution of Eq. (1) for determining $p_{\alpha}$ is performed by the collocation method for one collocation point $\alpha=0,5 \alpha_{0}$. The contact pressure function is determined as [1]

$$
p_{\alpha} \approx E_{0} \varepsilon \sqrt{\tan ^{2} \frac{\alpha_{0}}{2}-\tan ^{2} \frac{\alpha}{2}}
$$

where: $E_{0}=\left(e_{4} / R_{2}\right) \cos ^{2}\left(\alpha_{0} / 4\right)$

$e_{4}=4 E_{1} E_{2} / Z$ 


$$
\begin{aligned}
& Z=\left(1+\kappa_{1}\right)\left(1+v_{1}\right) E_{2}+\left(1+\kappa_{2}\right)\left(1+v_{2}\right) E_{1} \\
& E=2 G /(1+v) .
\end{aligned}
$$

The maximum contact pressures $p_{0}$ occur at $\alpha=0$. Then

$$
p_{0} \approx E_{0} \varepsilon \tan \left(\alpha_{0} / 2\right)
$$

The unknown contact angle $\alpha_{0}$ is determined by the equilibrium of the forces applied to the disk

$$
F=R_{2} \int_{-\alpha_{0}}^{\alpha_{0}} p_{\alpha} \cos \alpha d \alpha=4 \pi R_{2} E_{0} \varepsilon \sin ^{2}\left(\alpha_{0} / 4\right) .
$$

The tribocontact pressures acting in the bearing during the elements wear are determined as follows:

$$
p_{\alpha h=} p_{\alpha}+p_{h},
$$

where: $p_{h}$ is the change in initial pressures due to wear.

In order to find them, the following dependence is used

$$
p_{h}=E_{h} \varepsilon_{h} \sqrt{\tan ^{2} \frac{\alpha_{0 h}}{2}-\tan ^{2} \frac{\alpha}{2}}
$$

where: $E_{h}=c_{h}\left(e_{4} / R_{2}\right) \cos ^{2}\left(\alpha_{0 h} / 4\right)$, $c_{h}>0$ is the wear rate indicator.

In order to determine the half tribocontact angle $\alpha_{0 h}$ characterizing the contact zone during wear, a condition is used

$$
F=4 \pi R_{2} E_{0}\left(\varepsilon+c_{\alpha h} \varepsilon_{h}\right) \sin ^{2}\left(\alpha_{0 h} / 4\right)
$$

where: $\varepsilon_{h}=h_{k \max }\left(-K_{t}^{(k)}+h_{k}^{\prime}\right)$;

$h_{1}^{\prime}=h_{2} / h_{1}, h_{2}^{\prime}=h_{1} / h_{2}$ are relative wears in the tribosystem;

$K_{t}^{(1)}, K_{t}^{(2)}$ are the mutual overlapping factors bearing elements in the moving contact;

$c_{\alpha h}$ is the rate in the tribocontact angle increase.

$$
\begin{gathered}
h_{1}^{\prime}=\frac{h_{2}}{h_{1}}=\frac{\Phi_{1}(\tau)}{\Phi_{2}(\tau)}=\frac{B_{1} \tau_{10}^{m_{1}}\left(\tau-\tau_{20}\right)^{m_{2}}}{B_{2} \tau_{20}^{m_{2}}\left(\tau-\tau_{10}\right)^{m_{1}}} K_{t}^{(2)}, \\
h_{2}^{\prime}=\frac{h_{1}}{h_{2}}=\frac{\Phi_{2}(\tau)}{\Phi_{1}(\tau)}=\frac{B_{2} \tau_{20}^{m_{2}}\left(\tau-\tau_{10}\right)^{m_{1}}}{B_{1} \tau_{10}^{m_{1}}\left(\tau-\tau_{20}\right)^{m_{2}}} K_{t}^{(1)} ; \tau=f p_{0}
\end{gathered}
$$

$B, m, \tau_{0}$ are wear resistance characteristics of materials set by triboexperimental researches, $k=1$ for the ring and 2 for the disc, respectively.
The calculated ratio for the predictive estimate of the bearing durability at the given bushing wear $h_{1}=h_{k \max }$ is [1]

$$
\begin{aligned}
t= & \frac{-B_{k} \tau_{k o}^{m_{k}}}{v c_{h} \tau_{h} \Sigma_{k}\left(1-m_{k}\right) K_{t}^{(k)}}\left\{\left[\tau-\tau_{k 0}\right]^{1-m_{k}}\right. \\
& \left.-\left[\left(\tau-\tau_{k 0}\right)+c_{h} h_{k \max } \Sigma_{k} \tau_{h}\right]^{1-m_{k}}\right\}:
\end{aligned}
$$

where: $\Sigma_{1}=\left(-K_{t}^{(1)}+h_{1}^{\prime}\right), \Sigma_{2}=\left(K_{t}^{(2)}-h_{2}^{\prime}\right)$;

$$
K_{t}^{(1)}=1, K_{t}^{(2)}=\alpha_{0 \delta} / \pi \text {. }
$$

\section{SOLUTIONS}

The data for calculation: $N_{\max }=1500 \mathrm{~N}$, $N_{s}=1000 \mathrm{~N}, N_{\min }=500 \mathrm{~N} ; F=N / l ; D_{2}=20,25,50 \mathrm{~mm}$; $l=D_{2} ;$ at $D_{2}=20 \mathrm{~mm}-F_{\text {max }}=75 \mathrm{~N}, F_{\mathrm{s}}=50 \mathrm{~N}, F_{\text {min }}=25 \mathrm{~N}$; at $D_{2}=25 \mathrm{~mm}-F_{\text {max }}=60 \mathrm{~N}, F_{\mathrm{s}}=40 \mathrm{~N}, F_{\text {min }}=20 \mathrm{~N}$; at $D_{2}=30 \mathrm{~mm}-F_{\text {max }}=50 \mathrm{~N}, F_{\mathrm{s}}=33.3 \mathrm{~N}, F_{\text {min }}=16.67 \mathrm{~N}$; $\varepsilon=0.2,0.3 \mathrm{~mm} ; n_{1}=60 \mathrm{rpm} ; f_{G F}=f_{C F}=0.3-$ dry friction; $h_{1^{*}}=1.0 \mathrm{~mm}-$ allowable wear of the bushing.

The metal-polymer bearings with the following materials of elements were investigated:

1. Shaft - steel $0.45 \% \mathrm{C}$ normalized, grinding; modulus of elasticity and Poisson's ratio $E_{2}=210 \mathrm{GPa}, \mu_{2}=0.3 ; B_{2}=10^{13}, m_{2}=2$, $\tau_{20}=0.1 \mathrm{MPa}$.

2. Bushing:

- composite: glass-filled polyamide PA6 + 30GF, $E_{G F}=3.90 \mathrm{GPa}, \mu_{G F}=0.42$, volume content of filler $-30 \% ; B_{1 G F}=$ $6.67 \cdot 10^{10}, m_{1 G F}=1.9, \tau_{10}=0.05 \mathrm{MPa}$;

- composite: carbon-filled polyamide PA6 + $30 \mathrm{CF}, E_{C F}=5.20 \mathrm{GPa}, \mu_{C F}=0.42$, volume content of filler $-30 \% ; B_{1 C F}=24 \cdot 10^{10}, m_{1 C F}$ $=1.9, \tau_{10}=0.05$ МПа.

The results of the calculations are presented in Tables 1, 2 and Figures 3-6.

\section{Bearing with glass-polymer bushing}

Table 1 presents the results of the estimated evaluation of the tribocontact pressures during wear of the bushing. The steel shaft journal wears less by about three orders of magnitude.

The relative reduction of tribocontact pressures $p_{0 h} / p_{0}$ during bushing wear in this bearing with a change in load $N$, radial clearance $\varepsilon$ and shaft diameter $D_{2}$ is shown in Figures 2 and 3.

The results presented in the table and figures show that the reduction of the load leads to a 
Table 1. Maximum tribocontact pressures in the bearing with glass-polymer bushing

\begin{tabular}{|c|c|c|c|c|}
\hline \multirow{2}{*}{$h_{1}, \mathrm{~mm}$} & \multirow{2}{*}{$\mathrm{mm}$} & \multicolumn{3}{|c|}{$D_{2}, \mathrm{~mm}$} \\
\cline { 3 - 5 } & & 20 & 25 & 30 \\
\hline 0 & 0.2 & $15.0 / 12.2 / 8.6$ & $10.7 / 8.7 / 6.2$ & $8.1 / 6.6 / 4.7$ \\
\hline 0.5 & 0.2 & $11.6 / 10.4 / 7.6$ & $8.6 / 7.4 / 5.5$ & $4.7 / 5.7 / 4.2$ \\
\hline 1.0 & 0.2 & $5.6 / 6.05 / 5.6$ & $4.8 / 4.8 / 4.2$ & $9.95 / 3.35$ \\
\hline 0 & 0.3 & $18.3 / 14.9 / 10.5$ & $13.1 / 10.7 / 7.5$ & $9.1 / 7.55 / 5.4$ \\
\hline 0.5 & 0.3 & $16.2 / 13.6 / 9.9$ & $11.8 / 9.8 / 7.1$ & $7.9 / 6.76 / 5.1$ \\
\hline 1.0 & 0.3 & $13.4 / 11.8 / 9.0$ & $10.1 / 8.7 / 6.6$ & \\
\hline
\end{tabular}

Note: $p_{0 h}=15.0 / 12.2 / 8.6(\mathrm{MPa})$ at $N_{\max }=1500 / 1000 / 500(\mathrm{~N})$

decrease in the value of the initial contact pressures $p_{0}$ (Table 1), and, accordingly, to a decrease in the change of tribocontact pressures $p_{0 h}$, ie the ratio $p_{0 h} / p_{0}$ (Fig. 2). This trend is manifested in both smaller and larger radial clearances in the bearing.

Similar quantitative and qualitative trends occur with increasing diameter of the shaft journal (Fig. 3).

a)

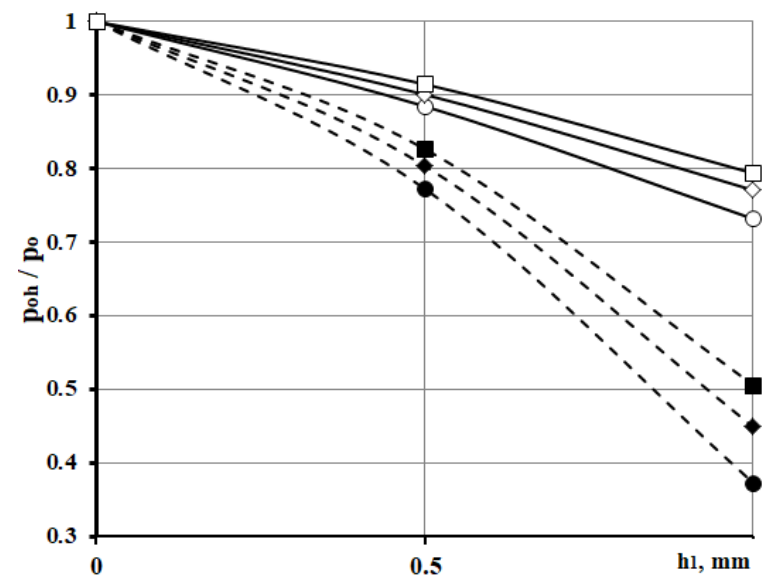

\section{Bearing with carbon polymer bushing}

Table 2 presents the results of the estimated evaluation of the tribocontact pressures during wear of the bushing.

The relative decrease in the tribocontact pressures $p_{0 h} / p_{0}$ during wear of the bushing in this bearing when changing the load $N$, the radial clearance $\varepsilon$ and the diameter $D_{2}$ of the shaft is shown in Figures 4 and 5.

b)

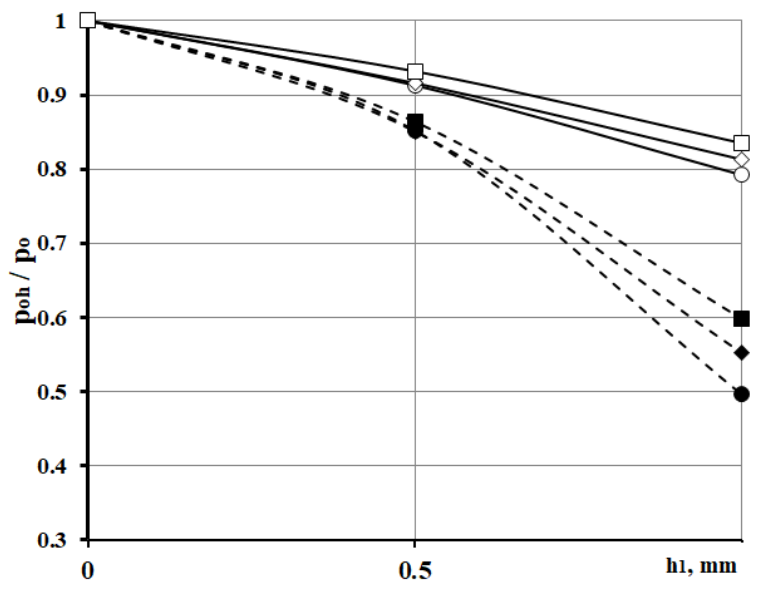

c)

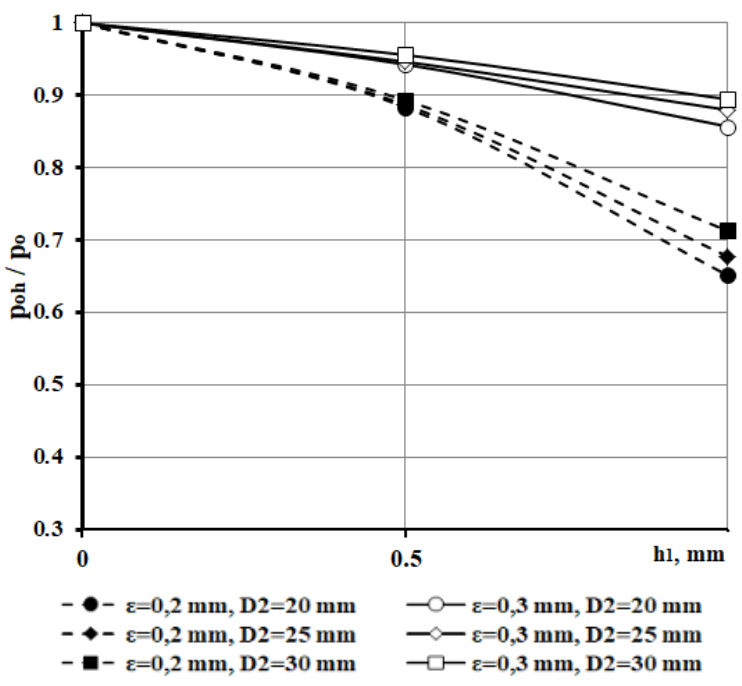

Fig. 2. The influence of load on the relative reduction of tribocontact pressures: a) $1500 \mathrm{~N}$; b) $1000 \mathrm{~N}$; c) $500 \mathrm{~N}$ 
a)

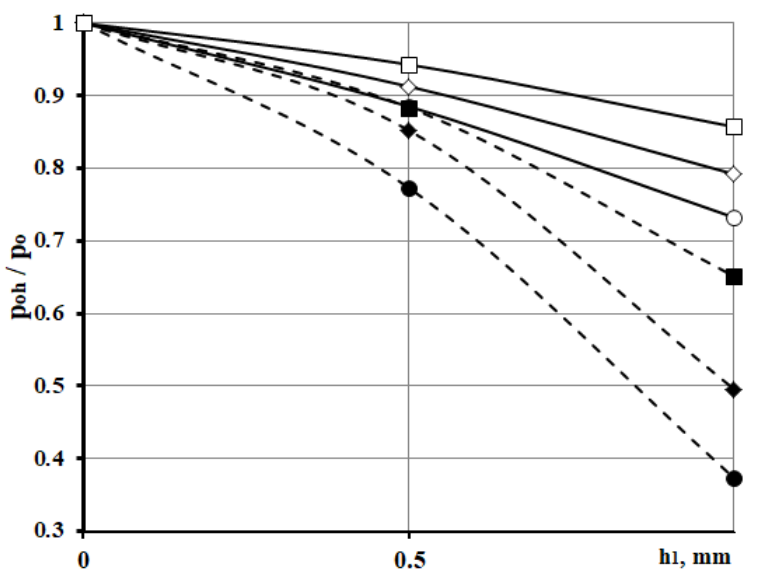

b)

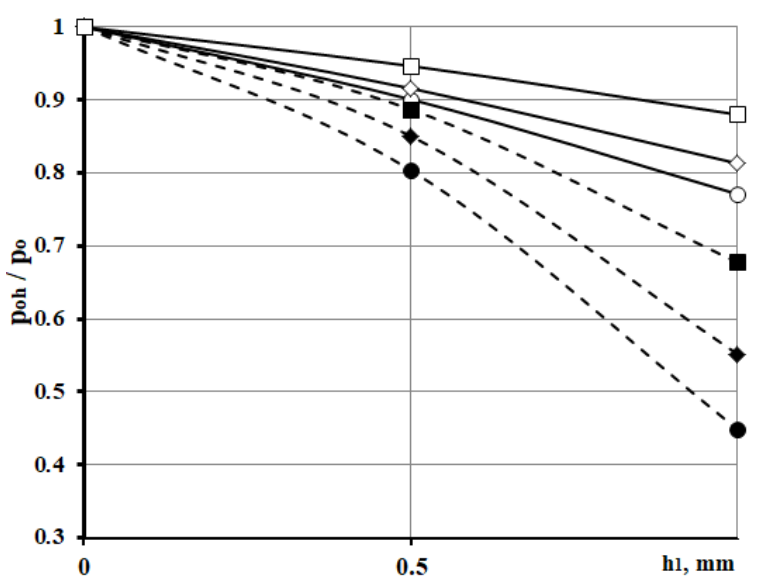

c)

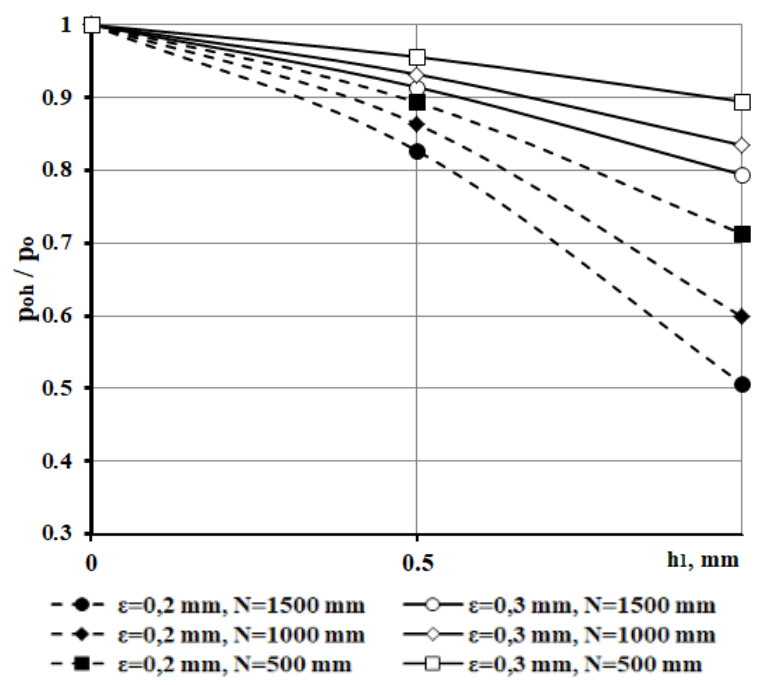

Fig. 3. The influence of the journal diameter on the relative reduction of tribocontact

The qualitative trends in the influence of the studied parameters on the change of initial contact pressures and tribocontact pressures are similar to those given in Figures 2 and 3. The comparison of the results in Table 1 and 2 shows that in bearings with a carbon-polymer bushing, the initial contact pressures are on average higher in $\sqrt{E_{C F} / E_{G F}}$ times than with a glass-polymer bushing. A similar ratio will also be in the case of tribocontact pressures.

The influence of the above-mentioned factors on the durability of hybrid bearings has also been studied. The results of the calculated evaluation of the bearing durability $t$ with the accepted allowable wear $h_{1^{*}}$ of the bushing are presented in Figure 6.

Table 2. Maximum tribocontact pressures in the bearing with carbon polymer bushing

\begin{tabular}{|c|c|c|c|c|}
\hline \multirow{2}{*}{$h_{1}, \mathrm{~mm}$} & \multirow{2}{*}{$\varepsilon, \mathrm{mm}$} & \multicolumn{3}{|c|}{$D_{2}, \mathrm{~mm}$} \\
\cline { 3 - 5 } & & 20 & 25 & 30 \\
\hline 0 & 0.2 & $17.2 / 14.25 / 9.9$ & $12.3 / 10.0 / 7.1$ & $9.5 / 7.6 / 5.4$ \\
\hline 0.5 & 0.2 & $14.1 / 12.1 / 8.9$ & $10.4 / 8.75 / 6.45$ & $5.1 / 6.75 / 4.95$ \\
\hline 1.0 & 0.2 & $8.3 / 8.1 / 6.95$ & $6.6 / 6.25 / 5.2$ & $11.6 / 9.3 / 6.6$ \\
\hline 0 & 0.3 & $21.0 / 17.4 / 12.1$ & $15.02 / 12.3 / 8.7$ & $10.8 / 8.8 / 6.3$ \\
\hline 0.5 & 0.3 & $18.5 / 16.1 / 11.5$ & $13.85 / 11.5 / 8.3$ & $9.55 / 8.0 / 5.9$ \\
\hline 1.0 & 0.3 & $15.4 / 14.3 / 10.6$ & $12.15 / 10.4 / 7.7$ & \\
\hline
\end{tabular}

Note: $p_{0 h}=15.0 / 12.2 / 8.6(\mathrm{MPa})$ at $N_{\max }=1500 / 1000 / 500(\mathrm{~N})$. 
a)

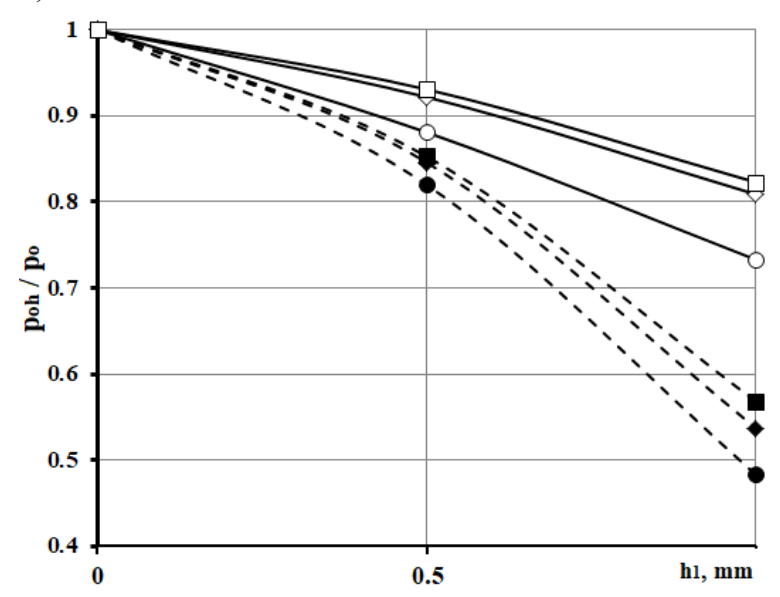

b)

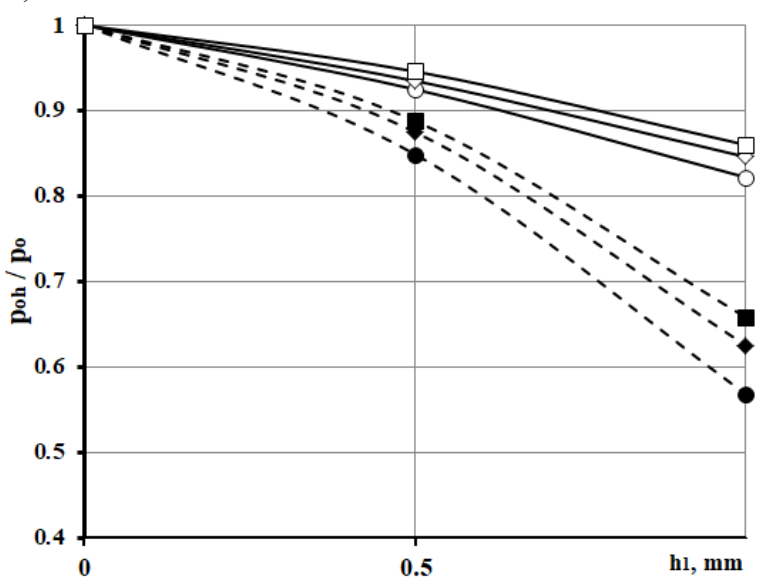

c)

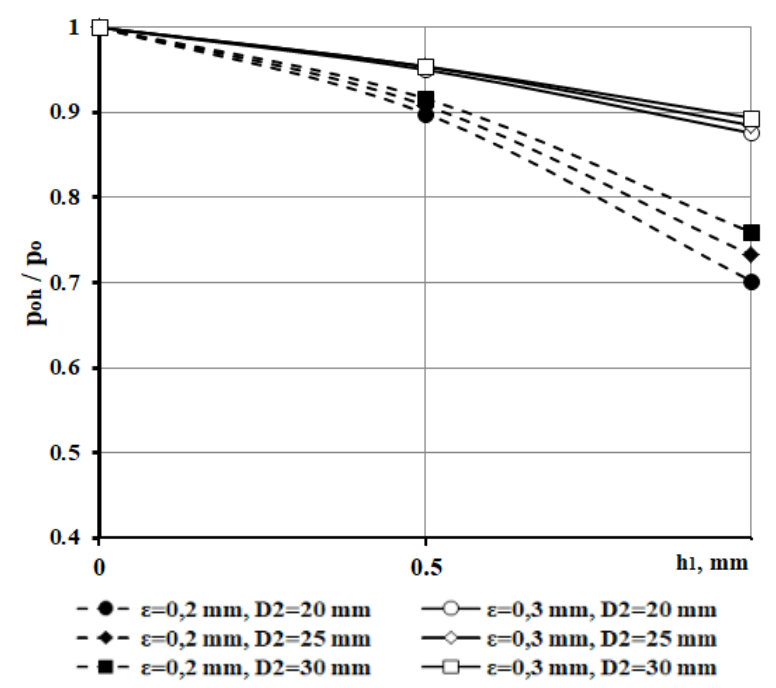

Fig. 4. The influence of load on the relative reduction of tribocontact pressures: a) $1500 \mathrm{~N}$; b) $1000 \mathrm{~N}$; c) $500 \mathrm{~N}$

The calculated durability of the bearing with a carbon-polymer bushing is $2.54 \ldots .2 .78$ times greater than the durability of the bearing with a glass-polymer bushing, i.e. on average 2.66 times. This corresponds to the ratio of the Young's modules of materials $2 E_{C F} / E_{G F}=2.67$ times.

\section{CONCLUSIONS}

The presented computational method of hybrid (metal-polymer) sliding bearings provides an effective and reasonable evaluation of their load capacity and durability at the design stage. The maximum contact pressures and their quantitative reduction at wear of the bushing, and also qualitative patterns of their relative change with change of the basic investigated factors of influence were established.
Increasing the load 3 times leads to an increase $\approx 1.73$ times in the maximum contact pressures, and increasing the diameter 1.5 times reduces them by about 1.84 times. Increasing the radial clearance causes them to grow in direct proportion. The maximum contact pressures in the bearings with a carbon-filled composite bushing will be greater than in the bearings with a glass-filled composite bushing $\approx \sqrt{E_{C F} / E_{G F}}$ times. The quantitative and qualitative patterns of the changes in the durability of bearings with allowable wear, taking into account the diameter of the bushing, radial clearance and radial load were established.

Increasing the load 3 times leads to the same reduction in the durability of bearings with a glass-polymer bushing, and 3.08 times for a bearing with a carbon-polymer bushing. The diameter increase 1.5 times increases the durability of 
a)

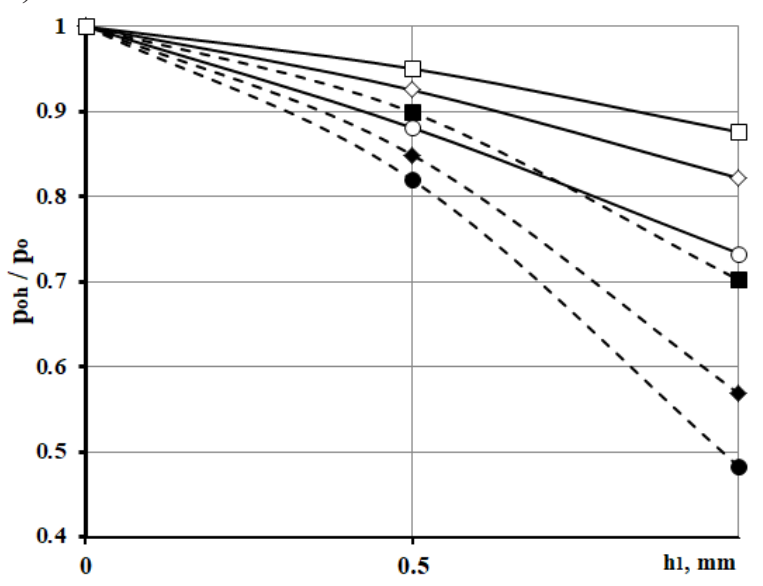

b)

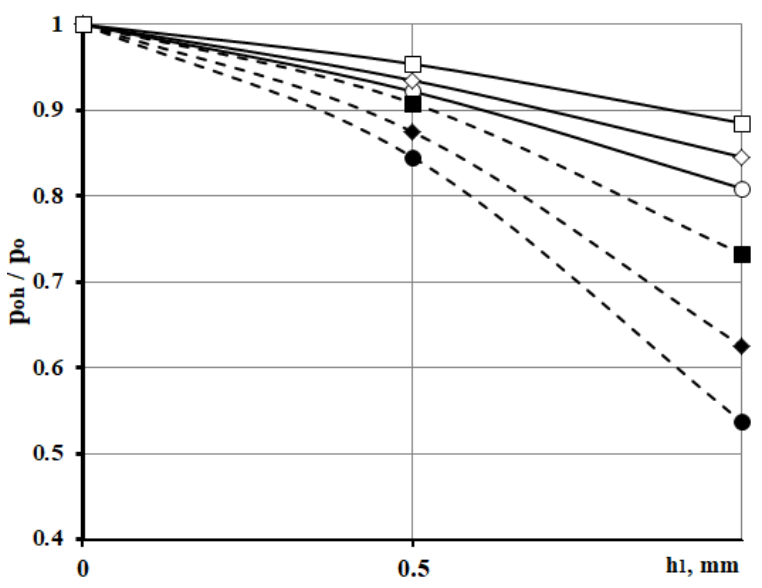

c)

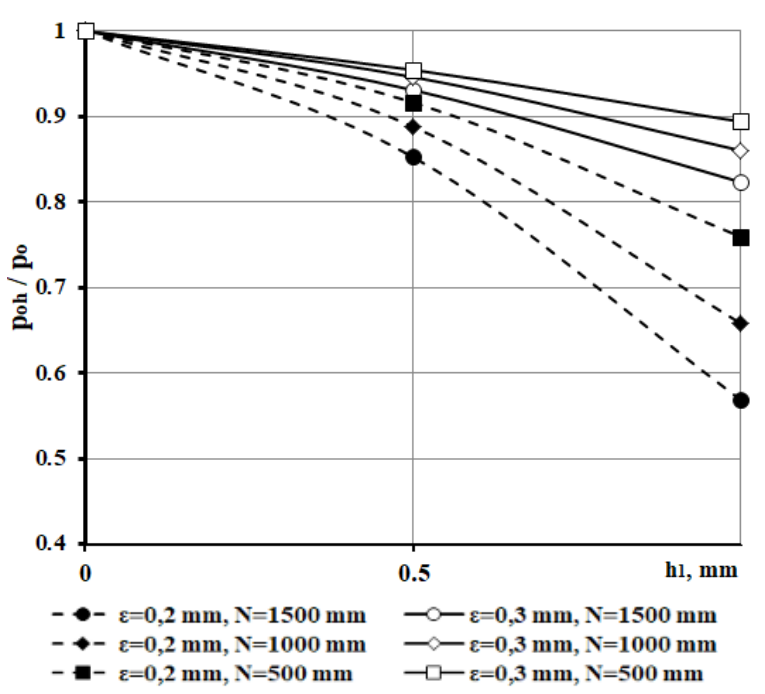

Fig. 5. The influence of the journal diameter on the relative reduction of tribocontact pressures: a) $20 \mathrm{~mm}$; b) $25 \mathrm{~mm}$; c) $30 \mathrm{~mm}$

a)

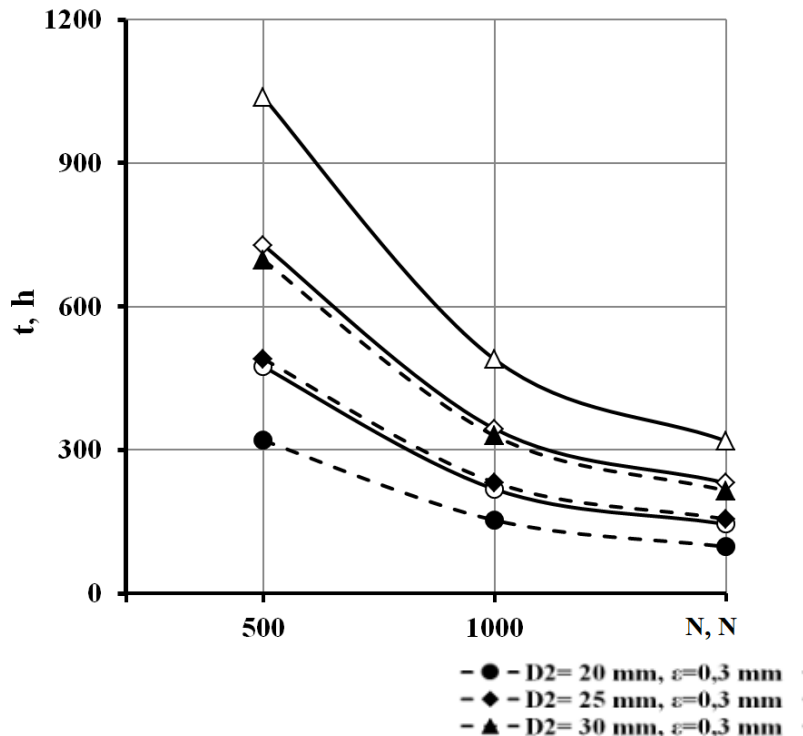

b)

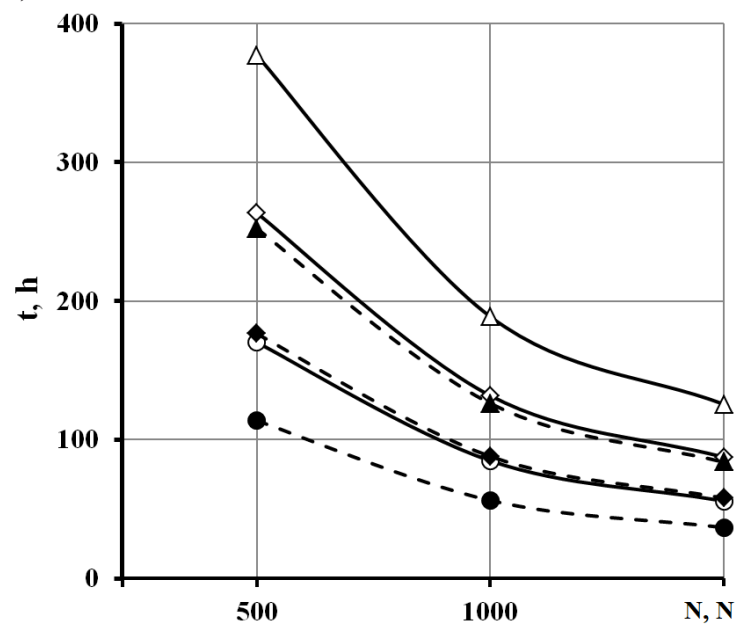

Fig. 6. Durability of hybrid bearings: a) bushing - carbon-filled polyamide PA6 + 30CF

b) bushing - glass-filled polyamide PA6 + 30GF 
bearings $\approx 2.25$ times. Increasing the radial clearance by 1.5 times reduces the durability of bearings in direct proportion. The calculated durability of bearings with a carbon polymer bushing will be on average $2 E_{C F} / E_{G F}$ times greater than the durability of bearings with a glass polymer bushing.

\section{REFERENCES}

1. Chernets M.V., Andreikiv O.E., Liebiedieva N.M., Zhydyk V.B. A model for evaluation of wear and durability of plain bearing with small non-circularity of its contours. Materials Science, 2, 2009, 279-290, https://doi.org/10.1007/ s11003-009-9176-5.

2. Chernets M., Chernets Ju. Generalized method for calculating the durability of sliding bearings with technological out-of-roundness of details. Proc. JMechE. Part J: Journal of Engineering Tribology, 229(2), 2015, 216-226, https://doi. org/10.1177/1350650114554242.

3. Dykha A., Marchenko D. Prediction the wear of sliding bearings. International Journal of Engineering \& Technology, 7(2.23), 2018, 4-8, doi: 10.14419/ijet.v7i2.23.11872.

4. 4. Dykha A., Sorokatyi R., Makovkin O., Babak O. Calculation-experimental modeling of wear of cylindrical sliding bearings. Eastern-European Journal of Enterprise Technologies, 89 (5(1)), 2017, 51-59, https://doi.org/10.15587/1729-4061.2017. 109638.

5. Goryacheva I.G. The mechanics of frictional interaction. Nauka, 2001.

6. Kragelsky I.V., Dobychin N.M., Kombalov V.S. Basics of friction and wear calculations. Mashinostroyeniye, 1977.

7. Kuzmenko A.G. Development of methods of con- tact tribomechanics. KhNU, 2010.

8. Rezaei A., Ost W., Van Paepegem W., De Baets P., Degrieck J. Experimental study and numerical simulation of the large-scale testing of polymeric composite journal bearings: Three-dimensional and dynamic modelling. Wear, 270, 2011, 431-438, doi: 10.1016/j.wear.2010.11.005.

9. Rezaei A., Ost W., Van Paepegem W., De Baets P., Degrieck J. A study on the effect of the clearance on the contact stresses and kinematics of polymeric composite journal bearings under reciprocating sliding conditions. Tribology International, 48, 2012, 8-14, https://doi.org/10.1016/j. triboint.2011.06.031.

10. Rezaei A., Paepegem W.V., De Baets P., Ost W., Degrieck J. Adaptive finite element simulation of wear evolution in radial sliding bearing. Wear, 296 (1-2), 2012, 660-671, https://doi.org/10.1016/j. wear.2012.08.013.

11. Sorokatyi R.V. Evaluation of efficiency of sliding bearings during reciprocation. Journal of Friction and Wear, 24(2), 2003, 136-143.

12. Sorokatyi R.V. Modeling the behavior of tribosystems using the method of triboelements. Journal of Friction and Wear, 23 (1), 2002, 16-22.

13. Sorokatyi R.V. Solution of the problem of wear of a fine elastic layer with a rigid bearing mounted on a rigid shaft using the method of triboelements. Journal of Friction and Wear, 24(1), 2003, 35-41.

14. Tepliy M.I. Determination of contact parameters and wear in cylindrical sliding bearings. Friction and Wear, 6, 1987, 895-902.

15. Usov P.P. Internal contact of cylindrical bodies of close radii when their surfaces wear out. Friction and Wear, 3, 1985, 404-414.

16. Zwieżycki W. Predicting the reliability of wearing machine elements. Institute for Sustainable Technologies, 1999. 